\title{
MAICAPI - METODOLOGIA PARA AVALIAÇÃO DE IMPACTOS E CUSTOS AMBIENTAIS EM PROCESSOS INDUSTRIAIS: ESTUDO DE CASO
}

\author{
Methodology fOR ASSESSMENT OF ENVIRONMENTAL IMPACTS AND COSTS IN \\ INDUSTRIAL PROCESSES: A CASE STUDY

\begin{abstract}
PaUlo Ricardo Santos da Silva
Engenheiro Químico. Mestre em Engenharia de Produção pela UFRGS

\section{FERNANDO GONÇALVES AMARAL}

Engenheiro Civil. Mestre pela UCL (Bélgica) e pela EPHE (França). Doutor em Ergonomia pela UCL (Bélgica). Professor Adjunto e Pesquisador do Programa de Pós-graduação em Engenharia de Produção da Escola de Engenharia da Universidade Federal do Rio Grande do Sul
\end{abstract}

Recebido: 03/11/05

\section{RESUMO}

A preservação do meio ambiente, o uso racional de recursos naturais e a mudança de postura da sociedade frente às questôes ambientais têm levado as indústrias a buscar um melhor desempenho nessa área. Aliado a esses fatores, está a constatação de que a geração de rejeitos é sinônimo de perdas econômicas. Desta forma, um melhor desempenho ambiental representa ganhos financeiros para a organização. Em vista disso, este artigo apresenta a Metodologia MAICAPI, desenvolvida para avaliar os impactos e os custos ambientais de processos industriais. Sua aplicação em uma indústria metalmecânica, fabricante de incineradores industriais, permitiu identificar quais as etapas do processo produtivo apresentam impactos ambientais críticos, revelando as operaçôes que mais contribuem para os custos ambientais dessa empresa.

PALAVRAS-CHAVE: Metodologia MAICAPI, avaliação de desempenho ambiental, avaliação de impacto ambiental,indústria metal-mecânica.

Aceito: 11/07/06

\section{ABSTRACT}

Nowadays, industries are searching a better environmental performance stimulated by changes in society behavior concerning to environmental issues and reasonable use for natural resources. In addition, companies realized that they have economic losses producing wastes. So, a better environmental perfomance means financial benefits to the organization. This work presents MAICAPI Methodology developed to evaluate environmental impacts and costs in industrial processes. This methodology was applied on an incinerator machine factory and it allowed to identify process phases whose environmental impacts were critics. Besides, the methodology application also identified operations with higher environmental costs in this company.

KEYWORDS: MAICAPI Methodology, environmental performance assessment, environmental impact assessment, metalmechanical industry.

\section{INTRODUÇÃO}

Historicamente constata-se que o homem sempre explorou os recursos naturais do planeta, gerando resíduos, sem se preocupar com seus efeitos sobre o meio ambiente (Moura, 2000). Partindo-se desse enfoque, as soluções para os problemas ambientais causados pelo homem sempre tiveram como diretriz a lei do menor esforço, ou seja, a eliminação dos seus efeitos nocivos consistia em afastar o poluente gerado, diluí-lo e dispersá-lo (Valle, 1996). Como conseqüência dessas ações, observouse a degradação de recursos naturais e a poluição do ar, da água e do solo. No entanto, a principal preocupação em relação aos problemas ambientais gerados por essas açôes é que seus efeitos podem não ser imediatos. Além disso, alguns apresentam graves conseqüências globais, mesmo que sua ocorrência seja localizada, como é o caso das emissóes gasosas que contribuem para o aquecimento da Terra (Azapagic, 1999).

De acordo com Zbontar e Glavic (2000), esta situação promoveu o surgimento da preocupação da sociedade com a qualidade do ambiente. Isto, associado à rigorosa legislação ambiental, foi responsável pela busca por formas de racionalizar o uso de recursos naturais e minimizar a geração de resíduos no ramo industrial.

Por outro lado, conforme Meinders e Meuffels (2001), a maioria das preocupações ambientais pode ser relacionada com aspectos econômicos, uma vez que a redução no consumo de materiais e de energia está diretamente ligada com benefícios financeiros, além das melhorias ambientais. Nesse sentido, hoje mais de 30.000 empresas no mundo estão utilizando sistemas voltados para a gestão ambiental, na busca por um melhor desempenho nessa área (Ammenberg \& Hjelm, 2002). De acordo com Bakshi (2000), isso tem motivado o desenvolvimento de técnicas para incorporar aspectos ambientais no projeto e na operação de processos industriais.

Dentro desse contexto, este artigo visa apresentar a aplicação da metodologia MAICAPI - Metodologia para Avaliação de Impactos e Custos Am- 
bientais em Processos Industriais - em uma indústria do setor metal-mecânico, cuja finalidade foi identificar os principais impactos ambientais produzidos no processo e os custos ambientais associados.

\section{FUNDAMENTOS \\ TEÓRICOS DA METODOLOGIA}

A MAICAPI foi desenvolvida para suprir a necessidade de uma abordagem capaz de avaliar, simultaneamente, impactos e custos ambientais em processos industriais. Para isso, foram empregados como bases teóricas a metodologia de Avaliação do Ciclo de Vida (Life Cycle Assessment - LCA), o Modelo Econômico de Controle e Avaliação de Impactos Ambientais - MECAIA, a Metodologia para a Contabilidade de Gerenciamento Ambiental (Environmental Management Accounting - EMA), o Método de Custeio Baseado em Atividades (Activity Based Costing - ABC) e a Matriz de Riscos, amplamente utilizada em avaliaçôes de riscos industriais.

Estruturalmente, a metodologia MAICAPI está dividida em três grandes fases, a saber: a) $1^{\text {a. }}$ Fase - Pré-análise: visa inicialmente formar um grupo de apoio na empresa onde será empregada essa metodologia, conhecer a organização e preencher o Questionário de PréAnálise (QPA) para poder traçar o seu panorama econômico-ambiental;

b) 2a. Fase-Análise: composta por uma série de etapas que direcionam as avaliações ambiental e econômica. Essa fase tem por objetivo identificar quais são as operaçôes críticas no processo produtivo, seus principais impactos e custos ambientais;

c) $3^{\text {a. }}$ Fase - Pós-Análise: nessa fase final são gerados cenários de melhoria para as operações críticas do processo, buscando minimizar os impactos ambientais identificados, os seus custos associados e estabelecer um plano de ação para que sejam implementadas tais possibilidades de melhoria.

A Tabela 1 detalha cada uma das etapas que compóem as fases da metodologia MAICAPI, suas finalidades e a forma como cada uma das bases teóricas contribuiu para o desenvolvimento dessa abordagem.

\section{METODOLOGIA}

\section{Formação de equipe de apoio}

A aplicação da metodologia MAICAPI inicia-se com a formação da equipe de apoio, um grupo multidisciplinar que estará envolvido em todas as etapas do trabalho. Para obter resultados mais expressivos, recomenda-se que esse grupo possua pessoas dos setores operacional, financeiro e de meio ambiente.

\section{Preenchimento do QPA}

A etapa seguinte da metodologia envolve o preenchimento do Questionário de Pré-Análise (QPA), o qual é constituído por questōes sobre: a empresa propriamente dita, seus produtos e processo produtivo, rejeitos gerados, seu sistema de custeio e a análise de desempenho da companhia.

Com base nas respostas obtidas, pode-se traçar um panorama econômico-ambiental da organização, verificando quais são as suas principais matérias-primas e produtos, tipos de rejeitos produzidos no processo, como essas

Tabela I - Caracterização geral da abordagem e suas bases teóricas

\begin{tabular}{|c|c|c|c|c|c|c|c|}
\hline \multirow{2}{*}{$\begin{array}{l}\text { Fases da } \\
\text { metodologia } \\
\text { proposta }\end{array}$} & \multirow[t]{2}{*}{ Etapas } & \multirow[t]{2}{*}{ Finalidades } & \multicolumn{5}{|c|}{ Bases teóricas } \\
\hline & & & (1) & (2) & (3) & (4) & (5) \\
\hline \multirow[t]{3}{*}{ Pré-análise } & $\begin{array}{l}\text { Formação da equipe } \\
\text { de apoio }\end{array}$ & Auxiliar na realização do trabalho & & & & & $\mathrm{X}$ \\
\hline & $\begin{array}{l}\text { Preenchimento do } \\
\text { QPA }\end{array}$ & Traçar perfil econômico-ambiental da empresa & & $\mathrm{X}$ & & & \\
\hline & Definições & $\begin{array}{c}\text { Especificar objetivos, abrangência e unidade } \\
\text { de referência }\end{array}$ & $\mathrm{X}$ & & & & \\
\hline \multirow[t]{5}{*}{ Análise } & $\begin{array}{l}\text { Mapeamento do } \\
\text { processo }\end{array}$ & $\begin{array}{l}\text { Desmembrar o processo produtivo em } \\
\text { operações de processamento }\end{array}$ & $\mathrm{X}$ & $\mathrm{X}$ & & $\mathrm{X}$ & \\
\hline & $\begin{array}{l}\text { Obtenção de } \\
\text { inventário }\end{array}$ & $\begin{array}{l}\text { Obter informaçôes sobre o processo } \\
\text { produtivo analisado }\end{array}$ & $\mathrm{X}$ & & & $\mathrm{X}$ & \\
\hline & Avaliação ambiental & $\begin{array}{c}\text { Analisar os impactos ambientais das } \\
\text { operações de processamento }\end{array}$ & $\mathrm{X}$ & & & & $\mathrm{X}$ \\
\hline & Avaliação econômica & $\begin{array}{l}\text { Analisar os custos ambientais das operaçōes } \\
\text { de processamento }\end{array}$ & & $\mathrm{X}$ & $\mathrm{X}$ & $\mathrm{X}$ & \\
\hline & $\begin{array}{l}\text { Interpretação dos } \\
\text { resultados }\end{array}$ & $\begin{array}{l}\text { Comparar as informações obtidas e priorizar } \\
\text { as operações de processamento }\end{array}$ & $\mathrm{X}$ & & & & $\mathrm{X}$ \\
\hline \multirow[t]{2}{*}{ Pós-Análise } & Geração de cenários & $\begin{array}{c}\text { Simular comportamento do processo em } \\
\text { diferentes condições e propor cenários } \\
\text { de melhoria }\end{array}$ & $\mathrm{X}$ & & & & \\
\hline & Plano de ação & $\begin{array}{c}\text { Propor açóes para alcançar o cenário de } \\
\text { melhoria gerado anteriormente }\end{array}$ & & & & & \\
\hline
\end{tabular}


informações estão inseridas na análise de desempenho da companhia e como funciona o seu sistema de custeio.

\section{Definições}

Assim como ocorre na metodologia LCA, na etapa de definições o grupo de apoio determina quais são os objetivos do estudo, a sua abrangência e a unidade funcional, ou seja, uma referência na qual são expressos os resultados da análise. Essa referência pode ser uma unidade de produto, um lote de produção, um quilograma de produto, sendo que a escolha dependerá do processo produtivo em questão.

\section{Mapeamento do processo}

Conforme utilizado nas metodologias LCA, MECAIA e ABC, após terem sido definidos os objetivos da análise, o passo seguinte é o mapeamento do processo produtivo e a obtenção de um diagrama de blocos do processo, visando estruturá-lo em operaçōes de forma seqüenciada. A estas operaçōes dá-se o nome de operações de processamento.

\section{Obtenção de dados físicos e econômicos}

Nesta etapa da metodologia, o grupo de apoio deve listar quais materiais são consumidos em cada operação de processamento, seus custos, os equipamentos utilizados, a disponibilidade de mão-de-obra para cada operação, os produtos, os subprodutos e os rejeitos gerados em cada uma dessas operaçôes. Essas informações devem ser obtidas tanto para as condições normais de operação, como também para condiçōes de operação anormais (partida e parada da unidade, variaçóes de regime de operação, manutenção, etc.).

Com base nas informações obtidas nessa etapa e no mapeamento do processo, é possível então estruturar o fluxograma do processo produtivo, o qual terá grande valia nas etapas subseqüentes. Nesse fluxograma, devem constar os materiais consumidos e gerados em cada operação de processamento, bem como o fluxo principal do processo produtivo.

\section{Avaliação ambiental}

Com base na lista de rejeitos gerados em cada operação de processamento, pode-se iniciar a avaliação ambiental, a qual envolve uma análise mais detalhada desses rejeitos. A partir de seus impactos ambientais reais ou potenciais, é possível identificar quais são as operaçôes de processamento críticas.

A primeira etapa da avaliação ambiental consiste em agrupar cada um dos rejeitos listados de acordo com a operação de processamento onde é gerado. A seguir, ele deve ser classificado segundo seu estado físico (resíduo, efluente ou emissão), seu destino (aterro industrial, estação de tratamento de efluente ou atmosfera), o meio diretamente impactado por ele (solo, água ou ar) e sua origem no processo produtivo (matéria-prima, insumo, produto intermediário ou limpeza de maquinário). Também é importante verificar em que condições cada rejeito é produzido, ou seja, durante o funcionamento contínuo dos equipamentos, na partida ou parada da unidade, em variações do regime de operação, etc.

O passo seguinte da avaliação ambiental envolve o preenchimento da Matriz de Avaliação Ambiental. Esta matriz é composta de duas partes: o alcance do impacto e a matriz de riscos ambientais propriamente dita. No que se refere ao alcance do impacto, deve-se identificar qual o efeito local, regional e global que cada intervenção ambiental pode ter sobre o meio ambiente. Para isso, é importante fazer consultas bibliográficas que auxiliarão o grupo de apoio nessa atividade. A seguir, cada intervenção identificada deve ser analisada em função de sua toxicidade, a fim de identificar se está acima ou abaixo dos limites estabelecidos pela legislação local.

Já o preenchimento da matriz de riscos ambientais é alcançado a partir da discussão do grupo de apoio a respeito da gravidade $(G)$ e da freqüência de ocorrência (FO) de cada intervenção. Quanto mais grave o efeito da intervenção sobre o meio ambiente, maior a pontuação a ser designada (valores entre 1 e 4). Da mesma forma, quanto maior a freqüência de ocorrência, maior será o escore atribuído a esse índice (valores entre 1 e 5). A partir desses dois índices pode-se determinar o efeito da intervenção ambiental, equivalente ao produto $(\mathrm{P})$ desses dois fatores. Assim, é possível classificá-la como:

a) crítica, se $\mathrm{P}$ for maior do que 9;

b) significativa, se $\mathrm{P}$ for superior ou igual a 6 e inferior a 9;

c) reduzida, se $P$ for superior ou igual a 4 e inferior a 6 ; que 4 .

d) desprezível, se P for menor do

A Tabela 2 apresenta a estrutura da Matriz de Avaliação Ambiental, exemplificando o seu preenchimento para uma determinada intervenção ambiental.

\section{Avaliação econômica}

Durante esta etapa, realiza-se a avaliação dos custos ambientais de cada operação de processamento. Nesta metodologia, adotam-se os conceitos de Kraemer (2002) e de Jasch (2003) para custo ambiental, ou seja, gastos relacionados às perdas de matérias-primas e insumos e os custos operacionais associados (custos de geração), que venham a ter efeitos negativos sobre o meio ambiente, os custos necessários para tratar os rejeitos gerados no processo (custos de tratamento e disposição ou, simplesmente, custos de correção) e os investimentos realizados na prevenção

Tabela 2 - Matriz de Avaliação Ambiental

Alcance do impacto

Matriz de riscos ambientais

\begin{tabular}{|c|c|c|c|c|c|c|c|c|c|c|}
\hline Operação & $\begin{array}{c}\text { Intervenção } \\
\text { ambiental }\end{array}$ & Local & Regional & Global & $\begin{array}{l}\text { Legislação } \\
\text { específica }\end{array}$ & $\begin{array}{c}\text { Condição } \\
\text { de Geração } \\
\end{array}$ & G & $\mathrm{FO}$ & $\mathrm{P}$ & Efeito \\
\hline $\begin{array}{l}\text { Recuperação } \\
\text { de matérias- } \\
\text { primas }\end{array}$ & $\begin{array}{l}\text { Efluente aquoso } \\
\text { contendo } \\
60 \text { ppm de fenol }\end{array}$ & $\begin{array}{c}\text { Elevação } \\
\text { da DQO } \\
\text { do efluente }\end{array}$ & $\begin{array}{l}\text { Poluição } \\
\text { das } \\
\text { águas }\end{array}$ & Ecotoxicidade & $\begin{array}{l}\text { Abaixo dos } \\
\text { limites de } \\
\text { toxicidade }\end{array}$ & Normal & 3 & 5 & 15 & Crítico \\
\hline
\end{tabular}

Legenda: (G) Gravidade; Freqüência de ocorrência (FO); Pontuação (P) 
de problemas ambientais e melhorias de processo sob esse aspecto (custos de prevenção).

A finalidade desta etapa da metodologia é identificar quais são as operações de processamento responsáveis pelo maior custo de geração e de tratamento e disposição de rejeitos. Além disso, pretende-se analisar os custos de prevenção de impactos ambientais, a fim de averiguar a postura da empresa frente à questão ambiental, ou seja, se seu comportamento é pró-ativo (custos de prevenção maiores do que os custos de correção) ou reativo (custos de correção maiores do que os custos de prevenção).

Seguindo a lógica do método $\mathrm{ABC}$, inicialmente deve-se distribuir os recursos consumidos no processo produtivo entre as operações de processamento, fazendo-se uso da Equação (1).

$\mathrm{CO}(\mathrm{j})=\mathrm{IN}(\mathrm{j})+\mathrm{MOD}(\mathrm{j})+\mathrm{E}(\mathrm{j})+\mathrm{CI}(\mathrm{j})$

em que:

j é o índice que caracteriza a operação de processamento analisada;

$C O(j)$ é o custo da operação $j$;

$I N(j)$ é o custo dos insumos utilizados em $j$;

$M O D(j)$ é o custo da mão-de-obra direta empregada em $j$;

$E(j)$ é o custo devido ao consumo de energia;

$C I(j)$ corresponde aos custos indiretos da operação $j$.

Cada atividade de processamento é responsável pela fabricação de produtos intermediários. No entanto, eventualmente também são gerados subprodutos, resíduos, efluentes e emissões. Assim, o passo seguinte da avaliação econômica consiste em determinar os custos de geração de rejeitos. Novamente, seguindo a lógica do método $\mathrm{ABC}$, é necessário distribuir os custos das operaçóes de processamento entre os produtos e os resíduos, valendo-se dos dados obtidos na etapa de obtenção de inventário, do fluxograma de processo e do emprego da Equação (2).

$\mathrm{CG}(\mathrm{i})=\mathrm{CM}_{\mathrm{i}}+\mathrm{w}_{\mathrm{i}} \cdot \mathrm{CO}(\mathrm{j})$

em que:

$C G(i)$ é o custo de geração do rejeito $i$; $C M_{i}$ é a parcela dos custos do material que originou o rejeito $i$;

$w_{i}$ é o fator que associa os custos operacionais da operação $j$ com a geração do rejeito $i$.

O fator $w_{i}$ utilizado na Equação (2) corresponde à razão entre a quan- tidade de rejeito $i$ gerado na operação $j$ e a quantidade total de material que sai dessa operação.

Já o custo de geração relacionado a uma determinada operação de processamento - $C G P(j)$ - é calculado através do uso da Equação (3).

$\operatorname{CGP}(\mathrm{j})=\sum_{\mathrm{j}=1}^{\mathrm{n}} \mathrm{w}_{\mathrm{i}} \cdot \mathrm{CO}(\mathrm{j})$

A etapa seguinte da avaliação econômica visa calcular os custos de tratamento e disposição de rejeitos - CTD $(j)$ - e distribuí-los entre as operações de processamento. Para isso, deve-se primeiramente identificar todos os recursos consumidos por essas atividades, tais como: materiais, energia gasta pelos equipamentos de tratamento de rejeitos, mão-de-obra empregada nessas atividades, gastos com transporte de resíduos, taxas de disposição de rejeitos em aterros industriais, entre outros. Logo após, é importante observar as relaçōes de causa-efeito entre o tratamento e disposição de rejeitos e as operações de processamento a fim de poder alocar esses custos em cada operação de processamento. A Equação (4) mostra como isso pode ser realizado:

$\mathrm{CTD}(\mathrm{j})=\sum_{\mathrm{i}=1}^{\mathrm{n}} \mathrm{x}_{\mathrm{ij}} \cdot \mathrm{CL}+\sum_{\mathrm{i}=1}^{\mathrm{n}} \mathrm{y}_{\mathrm{ij}} \cdot \mathrm{CR}+\sum_{\mathrm{i}=1}^{\mathrm{n}} \mathrm{z}_{\mathrm{ij}} \cdot \mathrm{CE}$

em que:

CL é o custo total com o tratamento de efluentes líquidos;

$C R$ é o custo total com o tratamento e disposição de resíduos sólidos;

$C E$ é o custo total com o tratamento de emissões gasosas;

$x_{i j}, y_{i j}$ e $z_{i j}$ são direcionadores de custo de tratamento de efluentes, disposição de resíduos e tratamento de emissóes, respectivamente, devido ao rejeito $i$ na operação $j$;

A partir dos custos de geração de rejeitos associados às operações de processamento e dos custos de tratamento e disposição de rejeitos em cada operação, pode-se determinar o custo ambiental de cada operação de processamento - $C A O P(j)$ - utilizando-se a Equação (5).

$$
\operatorname{CAOP}(\mathrm{j})=\mathrm{CGP}(\mathrm{j})+\mathrm{CTD}(\mathrm{j})
$$

Por fim, é necessário identificar quais as atividades realizadas na organização, cujo objetivo é evitar a geração de rejeitos e a ocorrência de impactos ambientais. A seguir, deve-se mensurar seus custos para que seja possível calcu- lar os custos de prevenção (CPV). Tais atividades envolvem o tratamento de águas, preparo e condicionamento de matérias-primas e auxiliares de processo, treinamento de operadores, auditorias ambientais e gastos com Sistema de Gestão Ambiental, se for o caso.

Assim, o custo ambiental do processo produtivo (CA) pode ser calculado de acordo com a Equação (6).

$\mathrm{CA}=\sum_{\mathrm{j}=1}^{\mathrm{n}} \mathrm{CAOP}(\mathrm{j})+\mathrm{CPV}$

\section{Interpretação dos resultados}

Com base nos resultados obtidos, durante as avaliações ambiental e econômica, é possível analisar o processo produtivo de forma mais profunda. Nesse sentido, a interpretação dos resultados visa identificar quais as operações de processamento são críticas, agora, considerando tanto o aspecto ambiental, como o econômico.

Nesta etapa, também são realizadas análises que permitem estabelecer algumas conclusões sobre o processo produtivo e a organização analisada, tais como:

a) quais são os principais impactos ao meio ambiente relacionados às condições de operação normal ou anormal;

b) identificar se esses impactos são devido à geração de resíduos, de efluentes ou de emissóes;

c) comparar a magnitude das parcelas que compóem os custos ambientais, ou seja, custos de prevenção, de tratamento e disposição e de geração de rejeitos;

d) verificar se há uma relação direta entre os impactos e os custos ambientais, ou seja, se as intervençôes, cujos efeitos ambientais são críticos, também são responsáveis pelas maiores parcelas de custos ambientais.

Com esses resultados, identificamse os pontos fracos do processo produtivo, para os quais são propostos cenários de melhorias que, posteriormente, serão desdobrados em planos de ação.

\section{Geração de cenários}

$\mathrm{Na}$ geração de cenários, as operaçōes de processamento classificadas como críticas, a partir da interpretação dos resultados, são simuladas em diferentes condições de operação, verificando-se o comportamento do 
processo quanto aos aspectos ambiental e econômico.

Nessa investigação podem ser modificadas as matérias-primas utilizadas na operação, alterados os parâmetros de processo da operação, analisadas as formas de reduzir a geração de rejeitos e, se for o caso, troca de equipamentos.

\section{Plano de ação}

Para finalizar a aplicação da metodologia MAICAPI, os cenários de melhoria que foram gerados na etapa anterior são apresentados à equipe de apoio. Cabe a esse grupo selecionar os cenários mais adequados as suas necessidades, desde que também satisfaçam os objetivos definidos no início do emprego da metodologia.

Para os cenários selecionados, é necessário estruturar um plano de ação, o qual deve conter basicamente as seguintes informaçôes:

a) o que deve ser feito (What?), ou seja, quais são os aspectos e impactos ambientais que serão tratados;

b) quando será feito (When?), isto é, os prazos para a execução de cada atividade planejada;

c) onde serão executadas as açōes programadas (Where?), ou seja, em qual operação de processamento;

d) por que essas ações serão executadas (Why?), isto é, que requisitos legais ou corporativos determinam a realização dessas atividades;

e) quem tem a responsabilidade de realizar a ação (Who?);

f) como será realizada a ação necessária para atingir a meta proposta (How?);

g) em termos de custos ambientais, o que esta ação irá acarretar para a empresa (How much?).

Uma vez estabelecido o plano de ação, conclui-se a aplicação da metodologia MAICAPI. Como as informaçōes já foram organizadas, o emprego dessa metodologia em outras situações fica facilitado, possibilitando inclusive o seu desdobramento para algumas operações de processamento específicas do processo produtivo.

\section{RESULTADOS}

A metodologia MAICAPI foi aplicada em uma indústria do setor metalmecânico responsável pela produção de incineradores industriais. Inicialmente, foi organizado o grupo de apoio, formado pelo gerente geral da unidade, pelo supervisor de produção e pelo encarregado de produção. Esse grupo, em um segundo momento, respondeu às perguntas do QPA.

Com base nessas respostas, verificou-se que a empresa não possuía Sistema de Gestão Ambiental implantado. Quanto à geração de rejeitos, observouse que a produção de resíduos de chapas de aço é o maior problema enfrentado por essa organização. Já as questōes da parte econômica revelaram que não há uma avaliação dos custos ambientais nessa empresa. Além disso, ela desconhecia o percentual dos custos operacionais devidos à manutenção da qualidade ambiental. Por fim, constatou-se que não existiam indicadores ambientais específicos para o processo analisado.

$\mathrm{Na}$ etapa de definição de objetivos e escopo da análise, foi estabelecido que o estudo iria abranger todo o processo produtivo de um dos modelos de incineradores fabricados por essa empresa. Essa avaliação tinha por finalidade identificar quais as etapas do processo apresentavam maior potencial de impacto sobre o meio ambiente e seu alcance, além de mensurar a magnitude das parcelas que compunham os seus custos ambientais.

Com o auxílio do grupo de apoio, foi elaborado o diagrama de blocos do processo produtivo e foram obtidas as informações que compuseram o inventário de dados físicos e econômicos. Tais informaçōes permitiram traçar o fluxograma do processo produtivo como pode ser observado na Figura 1.

Com base nas informaçóes obtidas durante a obtenção do inventário de dados do processo e, a partir da análise de seu fluxo produtivo, foi possível identificar quais as intervençôes ambientais geradas durante a produção do incinerador em questão. A Tabela 3 apresenta tais intervenções, agrupadas por operaçôes de processamento.

A partir das informações apresentadas na Tabela 3, concluiu-se que a operação de concretagem do incinerador era a responsável pela geração da maioria das intervençôes ambientais identificadas nesse processo. No entanto, para obter informações mais exatas sobre o seu desempenho ambiental, foi necessário preencher a Matriz de Avaliação Ambiental. Através dela, pôde-se distinguir as intervenções com efeitos críticos sobre o meio ambiente daquelas cujos efeitos poderiam ser desprezados e, desta forma, ter um panorama ambiental mais adequado do processo produtivo. Os resultados obtidos com essa avaliação estão no Anexo 1.

A partir do preenchimento da Matriz de Avaliação Ambiental observou-se que apenas quatro intervençóes ambientais possuíam efeito crítico sobre o meio ambiente: o efluente de lavagem de equipamentos, os resíduos de molde de aço usados na etapa de concretagem, os resíduos de concreto refratário também utilizados na etapa de concretagem e os resíduos de rebarba de torno produzidos na operação de usinagem. Outro aspecto relevante é que, praticamente, todas as intervenções provocam um aumento na quantidade de resíduos que a empresa necessita dispor em aterro sanitário. Como conseqüência regional, há uma elevação na quantidade de materiais nos aterros que contribuem para a proliferação de insetos e outros organismos patogênicos, vetores de doenças. Já em nível global, o principal efeito dessas intervenções é o uso inadequado do solo. Do ponto de vista da condição de geração dessas intervenções ambientais, concluiu-se que quase todas são produzidas em condições normais de operação do processo. Apenas o efluente de lavagem de equipamentos é produzido em condições anormais (limpeza de equipamento). Ainda, consultando a legislação federal para a classificação de resíduos sólidos (NBR 10.004), notou-se que as sobras de amianto geradas na operação de concretagem são resíduos classe I, ou seja, perigosos. Por isso, embora esse resíduo tenha ficado na categoria de efeito significativo ao preencher a Matriz de Avaliação Ambiental, inevitavelmente ele precisa ser considerado na proposição de ações de melhoria.

Por fim, constata-se que a operação de concretagem foi a que apresentou o maior número de intervençôes ambientais críticas e significativas, seguida pela operação de usinagem. Em vista disso, essas duas operaçôes foram selecionadas para serem tratadas na etapa de interpretação de resultados e geração de cenários de melhoria.

Já na etapa de avaliação econômica, primeiramente, foram mensurados os recursos consumidos pela empresa, os quais foram distribuídos entre as operações de processamento, seguindo a lógica do método ABC (Activity Based Costing). Tais recursos incluem, basicamente, custos de insumos, energia, mão-de-obra, aluguel e impostos. O resultado dessa distribuição pode ser visto na Tabela 4. 


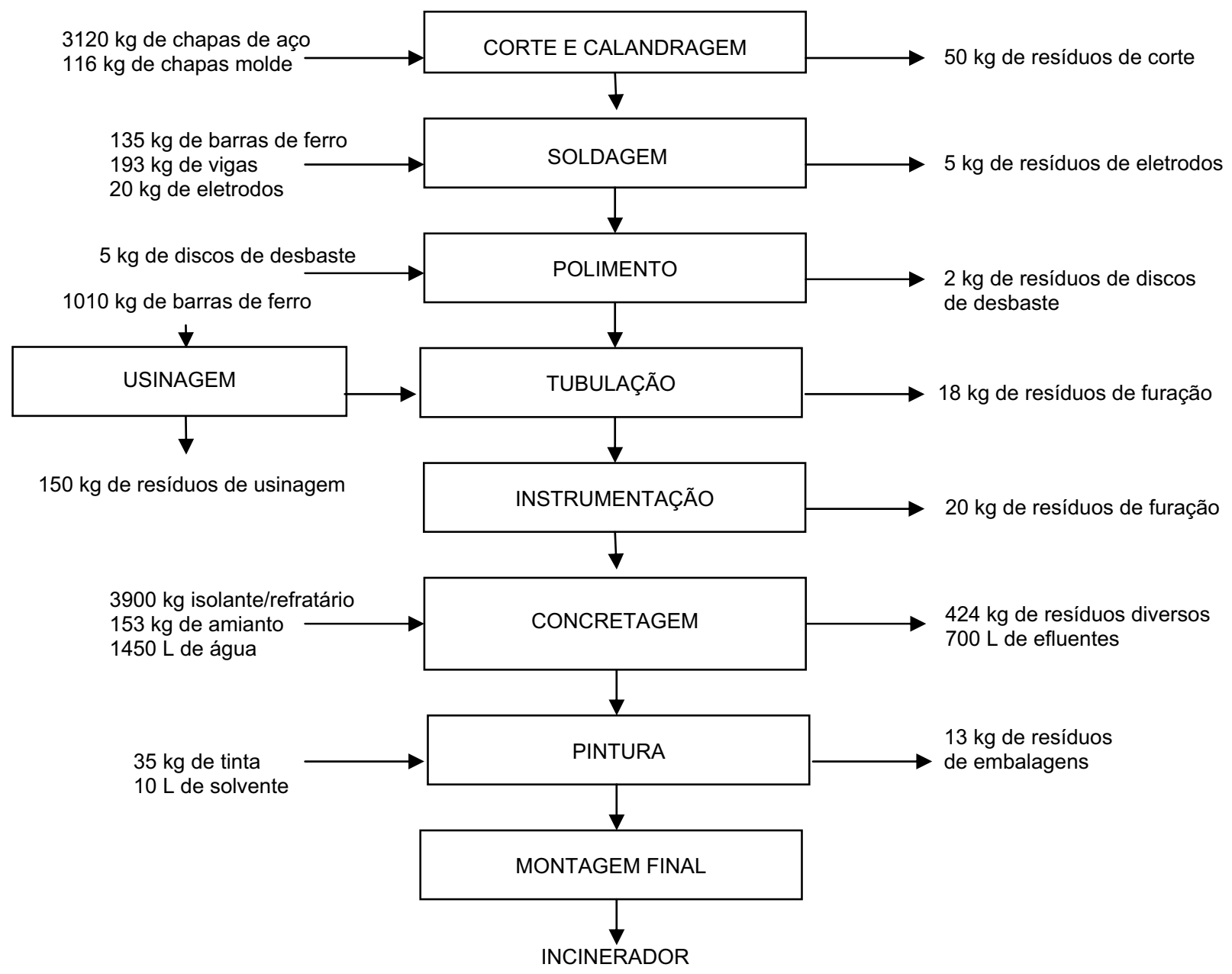

Figura I - Fluxograma do processo de fabricação de um incinerador

Tabela 3 - Intervenções ambientais geradas no processo produtivo analisado

\begin{tabular}{cc}
\hline Operação de processamento & Intervenção ambiental \\
\hline Corte e calandragem & Resíduos de corte de chapas \\
Soldagem & Resíduos de disco de corte \\
Polimento & Resíduos de eletrodo usado na operação \\
& Emissões de particulado gerado na operação \\
Instrumentação & Resíduos de disco de desbaste \\
Usinagem & Resíduos de furação \\
Tubulação & Resíduos de disco de corte \\
Concretagem & Resíduos de rebarba de ferro \\
& Resíduos de furação \\
& Efluente de lavagem de equipamento \\
& Resíduos de embalagem \\
& Resíduos de concreto isolante \\
& Resíduos de concreto refratário \\
& Resíduos de molde de aço \\
Pintura & Resíduos de sobras de amianto \\
& Resíduos de estopa \\
\hline
\end{tabular}


Tabela 4 - Panorama dos custos ambientais do processo produtivo analisado

\begin{tabular}{cccccc}
\hline Operação & $\begin{array}{c}\text { Montante de } \\
\text { recursos } \\
\text { consumidos na } \\
\text { operação }(\mathrm{R} \$)\end{array}$ & $\begin{array}{c}\text { Custo total de } \\
\text { perda de } \\
\text { materiais na } \\
\text { operação }(\mathrm{R} \$)\end{array}$ & $\begin{array}{c}\text { Custo de } \\
\text { geração } \\
\text { associado à } \\
\text { operação (R\$) }\end{array}$ & $\begin{array}{c}\text { Custo de } \\
\text { tratamento e } \\
\text { disposição de } \\
\text { rejeitos }(\mathrm{R} \$)\end{array}$ & $\begin{array}{c}\text { Custo ambiental } \\
\text { da operação de } \\
\text { processamento } \\
\text { (R\$) }\end{array}$ \\
\hline Corte e calandragem & 872,77 & 109,00 & 51,78 & 63,55 & 115,33 \\
Soldagem & $1.069,77$ & - & 1,42 & 6,22 & 7,64 \\
Polimento & 452,59 & - & 0,27 & 2,74 & 3,01 \\
Instrumentação & 503,96 & 72,73 & 2,95 & 26,38 & 29,33 \\
Usinagem & 745,13 & 630,00 & 110,66 & 186,66 & 297,32 \\
Tubulação & 479,66 & 90,06 & 1,92 & 22,40 & 24,32 \\
Concretagem & 827,04 & 986,67 & 92,13 & 527,87 & 620,00 \\
Pintura & 549,79 & 122,50 & 0,80 & 16,18 & 16,98 \\
Montagem final & 429,60 & - & - & - & - \\
TOTAL & $5.930,31$ & $2.010,96$ & 261,93 & 852,00 & $1.113,93$ \\
\hline
\end{tabular}

O passo seguinte da avaliação econômica consistiu na redistribuição dos custos das operaçóes de processamento entre os objetos de custo, ou seja, produtos intermediários e rejeitos produzidos em cada operação, usando a Equação (2). Os resultados obtidos estão sintetizados na Tabela 3. Através dos resultados apresentados nesta tabela, verificou-se que as operações de concretagem e usinagem eram responsáveis por mais de $70 \%$ dos custos de geração de resíduos nesse processo produtivo. Considerando o custo de perda de material, essas operações permaneceram em destaque, pois nelas era gerado um volume considerável de rejeitos com elevado custo associado.

O passo seguinte da avaliação de custos ambientais foi a verificação do custo total relacionado ao tratamento e disposição de rejeitos e sua redistribuição entre as operaçôes de processamento. Com o auxílio da equipe de apoio, verificou-se que a organização tinha gastos com a armazenagem e transporte dos rejeitos gerados no processo, em um montante de R \$ 852,00. Empregando-se a equação (4), esses gastos foram distribuídos entre as operações de processamento, sendo os resultados obtidos apresentados na Tabela 4.

Novamente, observou-se que as operações de concretagem e de usinagem são responsáveis pela maior parcela dos custos de tratamento e disposição dos rejeitos. Esse resultado já era esperado, uma vez que nessas operaçōes ocorre a maior geração de resíduos a ser disposto.
Posteriormente, com o auxílio da equação (5), foi possível calcular o custo ambiental de cada operação de processamento, como apresentado na Tabela 4.

Como conseqüência das constatações anteriores, as operações de concretagem e de usinagem foram responsáveis pela maior parcela dos custos ambientais entre as operações de processamento.

Por fim, restou avaliar os custos de prevenção. Juntamente com a equipe de apoio, fez-se uma estimativa de quanto a organização gastava com atividades de prevenção de problemas ambientais. Basicamente, esses gastos estavam relacionados a treinamentos semanais com a equipe operacional, os quais contabilizavam um custo total de R\$ 464,00. Assim, com o auxílio da Equação (6), pôde-se chegar ao valor do custo ambiental dessa organização.

$$
\mathrm{CA}=1.113,93+464,00=\mathrm{R} \$ 1.577,93
$$

A comparação entre os custos ambientais da empresa e os custos de prevenção mostra que esses representavam 29\% do montante. Dessa forma, pode-se afirmar que a organização analisada apresentava um perfil ambiental reativo.

O passo seguinte da aplicação da metodologia envolveu uma interpretação mais integrada dos resultados, pois já haviam sido concluídas as avaliações ambiental e econômica. Para facilitar essa análise, a Tabela 5 apresenta a síntese dos resultados obtidos durante a aplicação dessa metodologia.
A análise das informaçôes apresentadas na Tabela 5 revela que as intervençōes com efeito ambiental crítico são responsáveis por $65 \%$ dos custos de geração de rejeitos, $57 \%$ dos custos de correção (tratamento e disposição de resíduos) e, conseqüentemente, $63 \%$ dos custos ambientais relacionados com as operaçôes de processamento. Além disso, essa análise conjunta evidencia que as operações de concretagem e de usinagem são críticas nesse processo produtivo, tanto ambiental como economicamente.

A concretagem é responsável pela produção de 3 intervençōes críticas nesse processo produtivo, sendo que duas delas estão entre as que apresentam maior contribuição para os custos ambientais desse processo. Além disso, nessa operação é gerado um resíduo classificado como perigoso, segundo a legislação federal.

Por sua vez, a operação de usinagem apresentou apenas uma única intervenção ambiental, mas cujo efeito ambiental é crítico e responsável pela maior parcela dos custos ambientais. Como também pode ser observado através da Tabela 3, esse resíduo é responsável pela maior parcela de perda de matéria-prima nesse processo produtivo.

Essas conclusões evidenciam que no processo analisado há uma relação direta entre impacto ambiental e custos associados, ou seja, as intervençôes, cujo efeito ambiental é crítico, também são responsáveis pelas maiores parcelas de custos ambientais. 
Tabela 5 - Síntese dos resultados obtidos na aplicação da metodologia MAICAPI

\begin{tabular}{|c|c|c|c|c|c|c|c|c|}
\hline Operação & $\begin{array}{l}\text { Intervenção } \\
\text { ambiental }\end{array}$ & Efeito & $\begin{array}{c}\text { Custo } \\
\text { de } \\
\text { geração } \\
(\mathrm{R} \$)\end{array}$ & $\begin{array}{l}\text { Custo } \\
\text { de } \\
\text { correção } \\
(\mathrm{R} \$)\end{array}$ & $\begin{array}{c}\text { Custo } \\
\text { ambiental } \\
\text { operacional } \\
(\mathrm{R} \$)\end{array}$ & $\begin{array}{c}\% \text { do } \\
\text { custo } \\
\text { de } \\
\text { geração }\end{array}$ & $\begin{array}{l}\% \text { do } \\
\text { custo } \\
\text { de } \\
\text { correção }\end{array}$ & $\begin{array}{c}\% \\
\text { custo } \\
\text { ambiental }\end{array}$ \\
\hline \multirow[t]{6}{*}{ Concretagem } & $\begin{array}{l}\text { Efluente de lavagem } \\
\text { de equipamento }\end{array}$ & Crítico & 57,36 & - & 57,36 & 2,52 & 0,00 & 1,84 \\
\hline & $\begin{array}{l}\text { Resíduos de } \\
\text { embalagem }\end{array}$ & Significativo & 31,55 & 64,71 & 96,26 & 1,39 & 7,59 & 3,08 \\
\hline & $\begin{array}{c}\text { Resíduo de concreto } \\
\text { isolante }\end{array}$ & Significativo & 18,34 & 87,11 & 105,45 & 0,81 & 10,22 & 3,37 \\
\hline & $\begin{array}{c}\text { Resíduo de concreto } \\
\text { refratário }\end{array}$ & Crítico & 106,49 & 155,55 & 262,04 & 4,69 & 18,26 & 8,39 \\
\hline & $\begin{array}{c}\text { Resíduo de molde } \\
\text { de aço }\end{array}$ & Crítico & 576,64 & 144,35 & 720,99 & 25,37 & 16,97 & 23,07 \\
\hline & $\begin{array}{l}\text { Resíduo de sobras } \\
\text { de amianto }\end{array}$ & Significativo & 288,37 & 76,16 & 364,53 & 12,69 & 8,94 & 11,67 \\
\hline \multirow[t]{2}{*}{$\begin{array}{c}\text { Corte e } \\
\text { calandragem }\end{array}$} & $\begin{array}{c}\text { Resíduo de corte } \\
\text { de chapas }\end{array}$ & Significativo & 159,00 & 62,22 & 221,22 & 7,00 & 7,30 & 7,08 \\
\hline & $\begin{array}{l}\text { Resíduo de disco } \\
\text { de corte }\end{array}$ & Desprezível & 1,78 & 1,33 & 3,11 & 0,08 & 0,16 & 0,10 \\
\hline \multirow[t]{2}{*}{ Instrumentação } & $\begin{array}{l}\text { Resíduos sólidos } \\
\text { de furação }\end{array}$ & Desprezível & 75,51 & 24,89 & 100,40 & 3,32 & 2,92 & 3,21 \\
\hline & $\begin{array}{l}\text { Resíduos de disco } \\
\text { de corte }\end{array}$ & Desprezível & 0,17 & 1,49 & 1,66 & 0,01 & 0,18 & 0,05 \\
\hline \multirow[t]{2}{*}{ Pintura } & Resíduos de estopa & Significativo & 0,31 & 6,22 & 6,53 & 0,01 & 0,73 & 0,21 \\
\hline & $\begin{array}{l}\text { Resíduos de } \\
\text { embalagem }\end{array}$ & Desprezível & 122,99 & 9,96 & 132,95 & 5,41 & 1,17 & 4,25 \\
\hline Polimento & $\begin{array}{l}\text { Resíduo de disco } \\
\text { de desbaste }\end{array}$ & Desprezível & 0,27 & 2,74 & 3,01 & 0,01 & 0,32 & 0,10 \\
\hline Soldagem & Resíduos de eletrodo & Significativo & 1,42 & 6,22 & 7,64 & 0,06 & 0,73 & 0,24 \\
\hline Usinagem & $\begin{array}{l}\text { Resíduos de rebarba } \\
\text { de torno }\end{array}$ & Crítico & 740,66 & 186,66 & 927,32 & 32,59 & 21,91 & 29,68 \\
\hline Tubulação & $\begin{array}{c}\text { Resíduos sólidos } \\
\text { de furação }\end{array}$ & Desprezível & 91,98 & 22,40 & 114,38 & 4,05 & 2,63 & 3,66 \\
\hline
\end{tabular}

Finalmente, a partir dessas constataçôes, fica evidente que tanto a operação de concretagem, como a operação de usinagem, devem ser estudadas a fim de buscar uma melhoria econômicoambiental para esse processo produtivo. Isso é tratado na parte final da aplicação da metodologia a qual envolve a geração de cenários de melhoria e a elaboração do plano de ação.

Nessa etapa de geração de cenários de melhoria, foram elaboradas 4 possibilidades de melhoria para cada uma das intervençôes ambientais destacadas na Tabela 5 . Nos cenários, foi investigada a influência da redução na quantidade de rejeito produzido sobre o desempenho ambiental e econômico do processo. Em seguida, esses cenários foram apresentados à equipe de apoio que decidiu qual deles melhor respondia as suas necessidades e possibilidades de colocá-los em prática. A Tabela 6 apresenta os cenários escolhidos para cada situação

Para a geração de resíduos de amianto, o cenário de melhoria proposto foi a substituição dessa matériaprima por outra, que fosse capaz de satisfazer as necessidades de processo e cujo uso fosse permitido pela legislação federal. Assim, a partir da seleção dos cenários de melhoria, foram elaborados os planos de ação para alcançar cada uma das metas de redução estabelecidas nos cenários anteriores. Tais planos foram apresentados à equipe de apoio, finalizando-se a aplicação da metodologia MAICAPI. No entanto, como recomendação, foi estabelecido um período para que uma nova aplicação fosse feita no processo produtivo, a fim de verificar os resultados efetivamente alcançados.

\section{CONCLUSÕES}

O desenvolvimento da Metodologia para Avaliação de Impactos e Custos Ambientais em Processos Industriais - MAICAPI - foi motivado pela constatação de poucas abordagens na literatura tratando, em profundidade, dos impactos e dos custos ambientais simultaneamente.

A abordagem desenvolvida foi aplicada em uma indústria do setor metal-mecânico responsável pela produção de incineradores industriais. Seu objetivo era a realização de uma 
Tabela 6 - Cenários de melhoria escolhidos pela equipe de apoio

\begin{tabular}{|c|c|c|c|c|c|c|c|}
\hline \multicolumn{8}{|c|}{ Cenário escolhido para a redução de resíduos de concreto refratário } \\
\hline & \multicolumn{4}{|c|}{ Desempenho Ambiental } & \multicolumn{3}{|c|}{ Desempenho Econômico } \\
\hline $\begin{array}{c}\% \\
\text { Redução }\end{array}$ & G & FO & $\mathrm{P}$ & Efeito & $\begin{array}{c}\text { Custo de geração } \\
(\mathrm{R} \$)\end{array}$ & $\begin{array}{c}\text { Custo de correção } \\
(\mathrm{R} \$)\end{array}$ & $\begin{array}{c}\text { Economia por } \\
\text { incinerador }(\mathrm{R} \$)\end{array}$ \\
\hline 60 & 2 & 3 & 6 & Significativo & 42,63 & 69,87 & 149,54 \\
\hline \multicolumn{8}{|c|}{ Cenário escolhido para a redução de resíduos de molde de aço } \\
\hline & \multicolumn{4}{|c|}{ Desempenho Ambiental } & \multicolumn{3}{|c|}{ Desempenho Econômico } \\
\hline $\begin{array}{c}\% \\
\text { Redução }\end{array}$ & G & $\mathrm{FO}$ & $\mathrm{P}$ & Efeito & $\begin{array}{c}\text { Custo de geração } \\
(\mathrm{R} \$)\end{array}$ & $\begin{array}{c}\text { Custo de correção } \\
\qquad(\mathrm{R} \$)\end{array}$ & $\begin{array}{c}\text { Economia por } \\
\text { incinerador }(\mathrm{R} \$)\end{array}$ \\
\hline 50 & 3 & 2 & 6 & Significativo & 407,78 & 78,85 & 234,36 \\
\hline \multicolumn{8}{|c|}{ Cenário escolhido para a redução da quantidade de efluente de lavagem de equipamentos } \\
\hline & \multicolumn{4}{|c|}{ Desempenho Ambiental } & \multicolumn{3}{|c|}{ Desempenho Econômico } \\
\hline $\begin{array}{c}\% \\
\text { Redução }\end{array}$ & G & FO & $\mathrm{P}$ & Efeito & $\begin{array}{c}\text { Custo de geração } \\
(\mathrm{R} \$)\end{array}$ & $\begin{array}{c}\text { Custo de correção } \\
\qquad(\mathrm{R} \$)\end{array}$ & $\begin{array}{c}\text { Economia por } \\
\text { incinerador }(\mathrm{R} \$)\end{array}$ \\
\hline 40 & 2 & 4 & 8 & Significativo & 35,47 & - & 21,89 \\
\hline \multicolumn{8}{|c|}{ Cenário escolhido para a redução de rebarba de torno } \\
\hline & \multicolumn{4}{|c|}{ Desempenho Ambiental } & \multicolumn{3}{|c|}{ Desempenho Econômico } \\
\hline $\begin{array}{c}\% \\
\text { Redução }\end{array}$ & G & FO & $\mathrm{P}$ & Efeito & $\begin{array}{c}\text { Custo de geração } \\
\qquad(\mathrm{R} \$)\end{array}$ & $\begin{array}{c}\text { Custo de correção } \\
\qquad(\mathrm{R} \$)\end{array}$ & $\begin{array}{c}\text { Economia por } \\
\text { incinerador }(\mathrm{R} \$)\end{array}$ \\
\hline 60 & 2 & 4 & 8 & Significativo & 300,60 & 85,96 & 540,76 \\
\hline
\end{tabular}

avaliação econômica e ambiental completa do processo produtivo, a fim de identificar quais as etapas da produção desse equipamento apresentavam maior impacto sobre o meio ambiente. Além disso, desejava-se caracterizar os custos ambientais do processo, segundo as categorias de geração, tratamento e disposição e prevenção.

Como resultado, ficou evidenciado que os impactos ambientais desse processo eram devidos, basicamente, à geração de resíduos sólidos, os quais, em nível local, contribuem para o aumento de material que deve ser disposto pela empresa. Já em nível regional, isso implica no aumento de materiais nos aterros. De outra forma, a contribuição para o uso inadequado do solo e a exaustão de recursos não-renováveis foram os efeitos globais observados.

Também foi constatado que a etapa denominada de concretagem é a responsável pela maior parcela de resíduos produzidos no processo e pelo maior custo de tratamento e disposição de rejeitos. Além disso, nessa etapa concentram-se as intervençôes ambientais com efeitos críticos sobre o meio ambiente.

No que diz respeito à investigação quanto às categorias de custos ambientais, essa mostrou que os custos de geração constituem a maior parcela desses gastos, quando são considerados os custos de perdas de materiais. Essa conclusão vem ao encontro daquela obtida por Jasch (2003) na aplicação de sua metodologia, em que $80,4 \%$ dos custos ambientais estavam associados com a perda de material pelo processo. Quando o custo de perda de materiais não é inserido na parcela de custo de geração, os resultados mostraram que os custos de correção constituem a maior parcela de custos ambientais. Esse resultado permitiu concluir que a empresa analisada tem um perfil ambiental reativo. Por fim, é necessário salientar que os custos ambientais representam 11\% dos custos de produção do incinerador em estudo.

\section{REFERÊNCIAS}

AMMENBERG, J.; HJELM O. The connection between environmental management systems and continual environmental performance improvements. International Journal of Corporate Sustainability, v. 9, p. 183-192, 2002.

AZAPAGIC, A. Life cycle assessment and its application to process selection, design and optimisation. Chemical Engineering Journal, v. 73, p. 1-21, 1999.

BAKSHI, B. R. A thermodynamic framework for ecologically conscious process systems engineering. Computers and Chemical Engineering, v. 24, p. 1767-1773, 2000.
JASCH, C. The use of Environmental Management Accounting (EMA) for identifying environmental costs. Journal of Cleaner Production, v. 11, p. 667-676, 2003.

KRAEMER, T. H. Modelo Econômico de Gestão Ambiental. Tese de Doutorado em Engenharia de Produção - Universidade Federal de Santa Catarina, Santa Catarina, 2002.

MEINDERS, H.; MEUfFELS, M. Product chain responsibility - an industry perspective. International Journal of Corporate Sustainability, v. 8, p. 348-354, 2001

MOURA, L. A. A. Qualidade e Gestão Ambiental. 2 ed. São Paulo: Juarez de Oliveira, 2000.

VALLE C. E. ISO 14000 Qualidade Ambiental - $O$ desafio de ser competitivo protegendo o meio ambiente. 2 ed. São Paulo: Pioneira, 1996.

ZBONTAR L., GLAVIC P. Total site: wastewater minimization. Wastewater reuse and regeneration reuse. Resources, Conservation and Recycling, v. 30 , p. $261-275,2000$

Endereço para correspondência:

Fernando Gonçalves Amaral Departamento de Engenharia e Transportes

Universidade Federal do Rio

Grande do Sul

Av. Osvaldo Aranha, 99 - $5^{\circ}$ andar

90035- 190 Porto Alegre - RS - Brasil

Tel.: (5 I) 33 I 6-3545

E-mail: amaral@producao.ufrgs.br 


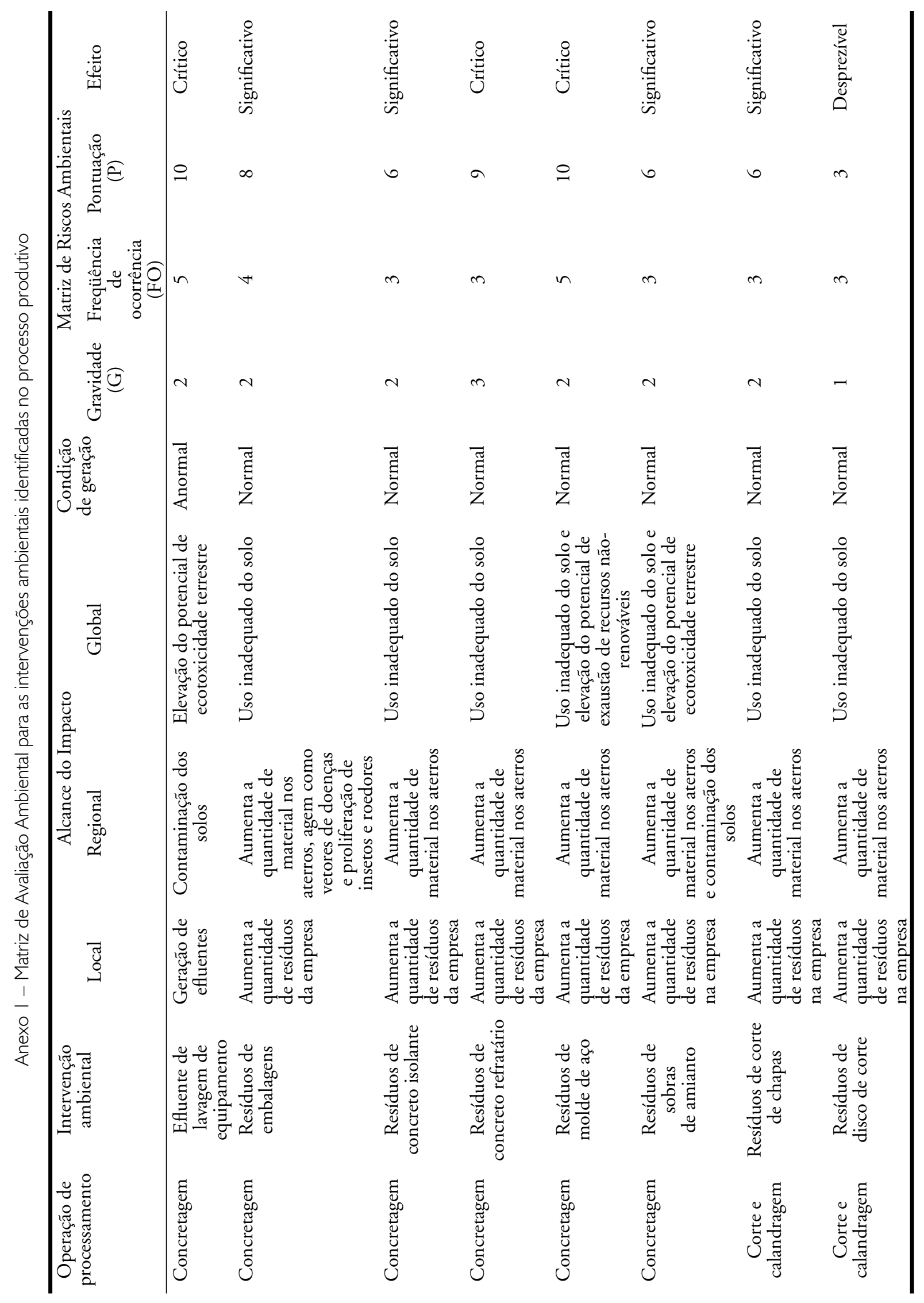




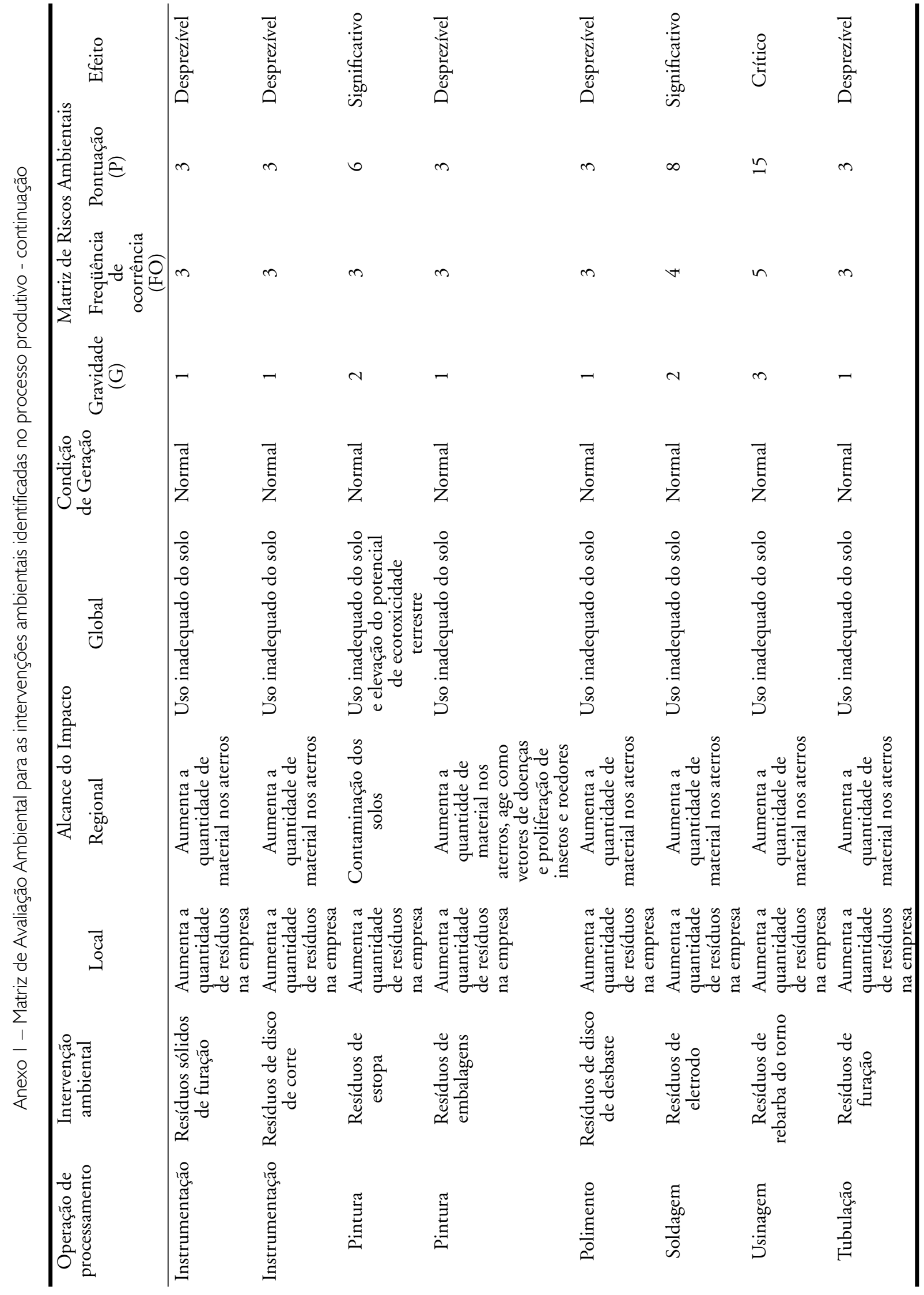

